ORIGINAL ARTICLE

\title{
Framed Stereotactic Brain Biopsy Outcome - Single Center Study
}

\author{
AURANGZEB KALHORO, A. SATTAR M. HASHIM \\ Neurospinal \& Cancer Care Institute, Karachi and Department of Neurosurgery \\ Jinnah Medical and Dental College, Karachi
}

DOI 10.36552/pjns.v24i2.452

\begin{abstract}
Objective: The objective of this present study was to assess the accuracy, result, and safety measures of stereotactic biopsy. The study was conducted at the Neurospinal \& Cancer Care Institute Karachi.

Material and Methods: After the approval from the ethical hospital committee, the study was conducted on 34 patients, in which 9 (26.4\%) were females, and 25 (73.5\%) were males. 34 consecutive patients with biopsy inclusion deep seated lesion, mid line pathology, eloquent area and operated surgery, previous radiation treatment were excluded, and after that, the biopsy report based surgery or radiotherapy treatment was decided.

Result: The biopsy underwent histopathological diagnosis proving Astrocytoma in 7 (20.5\%) patients out of which four were in the Eloquent area, tuberculosis diagnosed in 5 (14.7\%) patient, Oligodendroglioma diagnosed in $3(8.8 \%)$ patients, metastasis in $5(14.7 \%)$, Abscess in $4(11.7 \%)$ patient which was aspirated to maximum and sent for culture, Malignant tumor (grade 3 \& 4) 5 (14.7\%), Lymphoma in 2 (5.8\%) patient both were given radiation therapy Tumor necrosis 1 (2.9\%) case, and No tissue obtained in 2 (5.8\%) which was repeated later. No major complication or side effects were observed in the patient.

Conclusion: Stereotactic Framed biopsy is safe and accurate and can be used in deep seated lesions with high success rate, minimal complication and decrease surgical morbidity for patients, and it is comparable to updated methods.
\end{abstract}

Keywords: Stereotactic surgery, framed based, brain biopsy.

\section{INTRODUCTION}

A stereotactic brain biopsy is performed to know the disease histology before treating patients and selecting method of treatment. Usually, manifestation for deep seated or inoperable lesions. ${ }^{1}$ Stereotactic surgery has gone under innovation from frame-based to the frameless system as a result, there is the considerable unpredictable role of frameless to the precise accuracy advantage of frame-based methods. ${ }^{2}$ The stereotactic frame is the best choice for its reliability targeting for decades. Despite the restraint of both from framed to frameless with time tested, they both have proven equally reliable and accurate. ${ }^{3}$ Not as it was a magnetic resonance imaging guided stereotactic biopsy, but the approach robotic-assisted stereotactic has upgraded the security and close perfection of the result. With the passage of time, despite of an advancement in radioimaging has changed the fade in many ways, accurate histological diagnosis is an asset to treatment planning and management of intracranial pathologies and with the help of frame-based and frameless accuracy is around, $66-99 \%$ in framed biopsy and as $89-93 \%$ respectively in the literature ${ }^{5}$ and minimal rate of morbidity and motality. ${ }^{6}$ Frameless stereotactic targeting devices may miss target and miss diagnosis as compared with standard frame-based stereotaxy. ${ }^{7}$ Stereotactic frame systems are not only preferred for stereotactic biopsy, but are standard for deep brain stimulation (DBS) devices and psychological disorders. ${ }^{8}$ In Frameless stereotactic neuronavigation, 
devices are used still yet not and secure as framed systems, in terms of targeting lesion biopsies. ${ }^{9}$ Frame mounting is considered a significant step in stereotactic neurosurgery. Specific points of surface anatomy are of utmost importance and are used for accuracy. ${ }^{10}$

The noble art of performing a stereotactic biopsy as minimal invasive can be a safe, accurate, and the less morbid method to make a diagnosis which helps in managing according to diagnosis, helping to us decide mode of treatment, avoiding patient from long stay and unwanted surgery.

\section{MATERIAL AND METHODS}

\section{Study Setting}

A descriptive observational study was conducted from16-January-2015 to 18-January 2020 at Neurospinal \&the Cancer Care Institute, Karachi.

\section{Inclusion Criteria}

Deep seated lesion, eloquent area lesions and midline pathologies.

\section{Exclusion Criteria}

Previously operated cases, previous radiation treatment and coagulopathy.

\section{Data Collection}

The study was permitted by the ethical view board at our hospital. Moreover, consent was taken from all the patients for this study and data was collected. Proper history, neurological examination, CT scans brain and MRI brain was done. A total of 34 consecutive patients who underwent biopsy and later appropriately treated with surgical treatment, conservative or chemo radiotherapy was advised. Out of 34 patients, distributed as $25(73.5 \%)$ were men and 9 (26.4\%) were women. The mean age was 61 and the patients were between 34 to 84 age. Data were analyzed using SSPS version 22 and presented in the form of tables 1 and 2.

\section{Surgical Procedure}

The biopsies were performed under general anesthesia. In all lesions, Famous frame Cosman-Roberts-Wells (CRW) specialized stereotactic frame was used. The stereotactic head frame was fixed, and a fiducial head
Table1: Location of Lesion.

\begin{tabular}{|l|l|c|c|}
\hline & Site & $\mathbf{n = 3 4}$ & Percentage \\
\hline 1. & Frontal & 5 & $14.7 \%$ \\
\hline 2. & Temporal & 6 & $17.6 \%$ \\
\hline 3. & Thalamus & 12 & $35.29 \%$ \\
\hline 4. & Basal ganglia & 4 & $11.7 \%$ \\
\hline 5. & Brain stem & 4 & $11.7 \%$ \\
\hline 6. & Cerebellum & 3 & $8.8 \%$ \\
\hline
\end{tabular}

Table 2: Histopathological Diagnosis.

\begin{tabular}{|l|l|c|c|}
\hline & Lesion & $\mathbf{n = 3 4}$ & Percentage \\
\hline 1. & Astrocytoma & 7 & $20.5 \%$ \\
\hline 2. & Oligodendroglioma & 3 & $8.8 \%$ \\
\hline 3. & Metastasis & 5 & $14.7 \%$ \\
\hline 4. & Malignant tumors & 5 & $14.7 \%$ \\
\hline 5. & Abscess & 4 & $11.7 \%$ \\
\hline 6. & Radiation necrosis & 1 & $2.94 \%$ \\
\hline 7. & Tuberculosis & 5 & $14.7 \%$ \\
\hline 8. & Lymphoma & 2 & $5.8 \%$ \\
\hline 9. & Target missed & 2 & $5.8 \%$ \\
\hline & Total & 34 & \\
\hline
\end{tabular}

box was applied, then the patient was shifted for CT or (MRI) brain was to calculate the coordinates accordingly (Figure-1). After imaging, the patient was shifted to Operation Theater and positioned supine with the head fixed. Biopsy was taken through with a burr hole, under general anesthesia, burr hole was made, the point of the entry point was anterior to their coronal structure, $3 \mathrm{~cm}$ lateral to mid line and $2.5 \mathrm{~cm}$ anterior to the coronal suture as it was considered the safer surgery method in this area of the human brain. As for the Lesion in the brain stem, the perpendicular coronal plane to the head ring was performed. The direction utilizing was chosen to maintain a strategic distance from the ventricles and to decide how distant along the side to put the burr gap within the operating room. Moreover, coordinates or $\mathrm{X}, \mathrm{Y}$, and $\mathrm{Z}$ were already measured with a CT scan. Plus, the biopsy needle distance is measured, and a calculated biopsy was taken, and if any cyst or abscess found it was 
aspirated. Operating time was 120 minutes approx. The patients were kept under cover prophylactic antiepileptic, ceftriaxone and gentamycin and discharge on the $2^{\text {nd }}$ post-operative day.

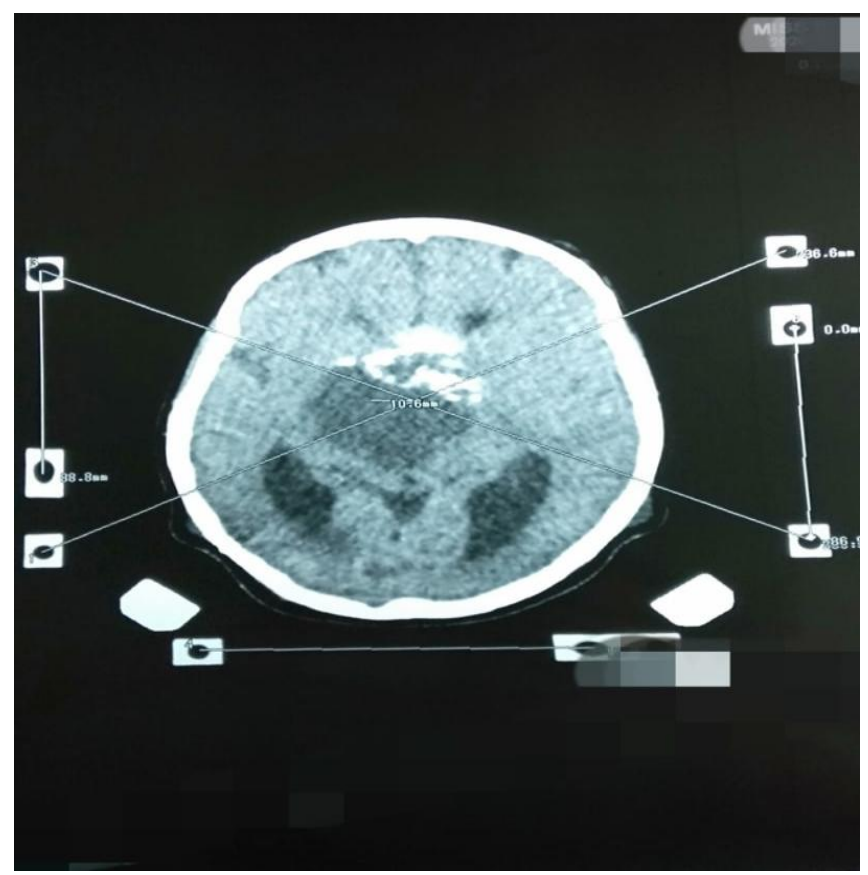

Fig. 1: Representation of the XYZ Coordinates Calculation on CT Scan.

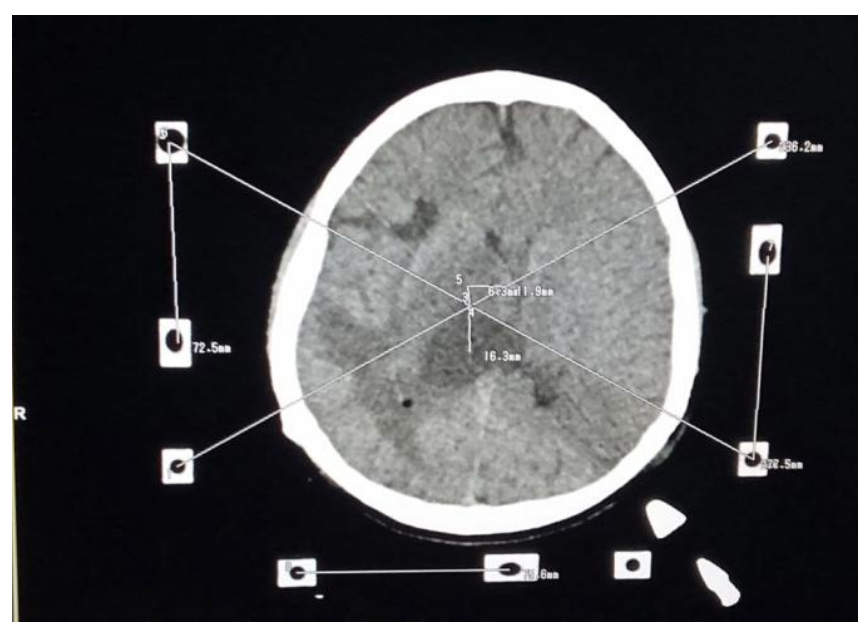

Fig. 2: Double Target Calculation for Stereotactic Biopsy for Cystic and Solid Part of Tumor.

\section{RESULTS}

The biopsy underwent histopathological diagnosis proving Astrocytoma in $7(20.5 \%)$ patients out of which three were in the Eloquent area referred for
Gamma-knife surgery while four cases were operated, tuberculosis diagnosed in $5(14.7 \%)$ patient, two patient were operated for mass effect while three were kept under Anti-tuberculosis treatment till complete recovery, Oligodendroglioma diagnosed in $3(8.8 \%)$ patients all cases were operated later, metastasis in 5 (14.7\%) patient in 2 was single lesion they write operated while, three patients had multiple lesion they were referred for chemotherapy and radiotherapy, Abscess in $4(11.7 \%)$ patient which was aspirated to maximum and sent for culture, Malignant tumor (grades 3 \& 4) 5 (14.7\%) cases out of which three were operated due to mass effect and 2 cases were treated with chemotherapy, Lymphoma in $2(5.8 \%)$ patient, Tumor necrosis 1 (2.9\%) case, and No tissue obtained in $2(5.8 \%)$ which was repeated later. No major complication or side effects were observed in the patient.

\section{DISCUSSION}

Bernstein et al, ${ }^{11}$ preformed 300 serial intra-axial brain lesion stereotactical biopsies for a total of nineteen patients $(6.3 \%)$ while 5 died during the procedure; having a diagnosis of Glioblastoma. Remaining 14 patients $(4.7 \%)$ developed neurological deficits due to hemorrhage. Mostly mild and of transient type. They concluded that Stereotactic biopsy has less complication rate and less morbidity compared to craniotomy. While, in our study, we had less number of the patient, plus we did not observe such major complication may be due to a limited number of patient studies and experienced faculty.

In study of Hall et al, ${ }^{12} 134$ stereotactic brain biopsies were conducted. Computed tomographyguided in 85 patients around (63\%) and 49 biopsies of patients were performed with the help of magnetic resonance imaging around (37\%). Right side of hemisphere of the brain had a share of 64 pathologies, that is $48 \%$, while $61(45 \%)$ in the left,62 were malignant brain tumors (46\%), 24 were benign brain tumors $(18 \%)$, and 20 were infections $(15 \%)$ and five biopsies (4\%), diagnostic yield measurement of $96 \%$. However, the neurological shortage after the biopsy was conducted, and the morbidity rate was rated at $0.7 \%$. One patient had a fatal hemorrhage during the biopsy process due to the high vascularity of tumor while we mostly used CT scan based calculations for our study. We did not had any death or morbidity in patients, while common lesion biopsies we came across was the astrocytoma, followed by malignant 
tumor and metastasis.

Lu et al, ${ }^{13}$ had $100 \%$ constructive diagnosis in all 50 cases in the magnetic resonance imaging intraoperatively iMRI group, although in four cases, the biopsy was not accurate from the expected point due to which repeat biopsy was done. However, no severe complications were observed in the iMRI grouping, bleed at the puncture area was noted in 2 patients within the control group. Moreover, no death was recorded in either group. While we only had two cases where the target was deviated while similar to their study, we did not have any major complications. Their study used more advance technique, and we stayed will traditional procedures, however the results are comparable.

Cheng et $a{ }^{14}{ }^{14} \mathrm{~A}$ total number of 145 patients undergo Stereotactic Biopsy among 18 (12.4\%) in the pineal region,16 (11.0\%) sellar part, brainstem had 111 (76.6\%). Biopsy accomplished 16/16 (100\%), $18 / 18(100 \%)$, and $107 / 111$ (96.4\%), the sellar region, pineal region, and brainstem were achieved patients, respectively. No major complications were documented in sellar or pineal, while it occurred in brain stem $17 / 111$ patients $(15.3 \%)$. While in our study, we did not have any biopsy from sellar, pineal gland we did not receive a sellar or pituitary region biopsy while we done brain stem biopsy not had any major complication as mentioned in their research Hamisch et al, ${ }^{15}$ performed 189 patients with 511 procedures. Lesions were localized in the thalamus (4.3\%), Sella (7.8\%), basal ganglia (17.0\%), brainstem, pineal region $(11.5 \%)$ and corpus callosum study had a zero rate of mortality and $0.4 \%$ and $9.6 \%$ was permanent and the transient morbidity rate was respectively. While, in $99.2 \%$ the Histological analysis was possible while compared to our study, 95\% diagnostic result, while we did not perform much procedure on sella, pine all area and, similarly, we had no mortality in our study.

Sciortino et al, ${ }^{16}$ in their study judgment, was performed on $93.6 \%$ having 9 biopsies ensuing the non-accurate. Hemorrhage occurred in $2.1 \%$. Moreover, in this, no procedure had mortality. Five days was the average stay in the hospital, with the mean surgical time of sixty minutes and compared to our study, stay time was two days postoperatively, no hemorrhage was observed in the study, and the diagnostic point was about $95 \%$ diagnostic results while similarly no mortality was observe.

Smith et al, ${ }^{17}$ did a study on 213 patients, and among them there were 74 frameless and 139 frame- based cases. They found that no major differences between two the frameless biopsies and frame-based groups when compared to their overall diagnostic accuracy, the amount of non-diagnostic procedure, demographics, or procedure complications. Mean operating time between and frameless and Framebased biopsies were $185+/-6$ and $114+/-3$ minutes, respectively. Their study showed that no significant difference observed based on this study, both the approaches/procedures were effective at equal level. While, our study did not have two group studies, we performed all studies with the CRW frame based on a calculation CT scan with time frame biopsy average time 120minutes.

Neumann et al, ${ }^{18}$ conducted a retrospective study of 500 cases using FBSBs utilizing iMRI were compared to a historical control of hundred procedures of biopsy with conventional workflows CT and magnetic resonance imaging image fusion. Their study showed no significant difference in diagnostic and complication rate among 2 groups. Hence FBSB utilizing 1.5T iMRI is an accurate, effective and yes a safe method and provides comparable results to the conventional stereotactic method.

Nishihara et $\mathrm{al}^{19}$ studied about the safety of stereotactic biopsy with they performed 58 times in fifty-six patients (male: 29, female: 27), 58 biopsies diagnoses were recognized, with, 8 of Mets, brain SOL thirty-five cases, nine of malignant lymphoma, and leukemia, diagnose of germ cell tumor in two patients, 2 cases of abscess in 2 cases, diagnose of necrosis in one case, and one case with normal tissue, hemorrhage with in tumor was in 3 cases (5.2\%) also having neurological deficits has occurred. They were surgical removal and Glioma was diagnosed. In their study, thalamus \& basal ganglia showed the risk of morbidity, while in our study, in contrast we did not have any hemorrhage among patient nor neurological deficit was found and we used CRW frame by an experienced neurosurgeon and no neurological defect.

\section{CONCLUSION}

Stereotactic Framed biopsy is safe and accurate and can be used in deep seated lesions with high success rate, minimal complication, and decreases a surgical morbidity for patients, and it is comparable to updated methods. 


\section{REFERENCES}

1. Jackson RJ, Fuller GN, Abi-Said D, Lang FF, Gokaslan ZL, Shi WM, Wildrick DM, Sawaya R. Limitations of stereotactic biopsy in the initial management of gliomas. Neuro-oncology, 2001; 3 (3): 193-200.

2. Kitchen ND, Lemieux L, Thomas DG. Accuracy in frame-based and frameless stereotaxy. Stereotactic and Functional Neurosurgery, 1993; 61 (4): 195-206.

3. Palys V, Holloway KL. Frameless functional stereotactic approaches. In Current Concepts in Movement Disorder Management, 2018 Vol. 33: pp. 168-186. Karger Publishers.

4. Chen Y, Godage I, Su H, Song A, Yu H. Stereotactic Systems for MRI-Guided Neurosurgeries: A State-ofthe-Art Review. Annals of Biomedical Engineering, 2019; 47 (2): 335-53.

5. Özek E, Seyithanoğlu H, Kitiş S, Dündar TT, Tekin A, Hatiboğlu MA. Frameless Neuronavigation Assisted Brain Biopsy: Safety, Efficiency and Our Experience. Bezmialem Science, 2019; 7 (2): 145-50.

6. Verploegh IS, Volovici V, Haitsma IK, Schouten JW, Dirven CM, Kros JM, Dammers R. Contemporary frameless intracranial biopsy techniques: Might variation in safety and efficacy is expected? Acta Neurochirurgica, 2015; 157 (11): 2011-6.

7. Widmann G, Schullian P, Ortler M, Bale R. Frameless stereotactic targeting devices: technical features, targeting errors and clinical results. The International Journal of Medical Robotics and Computer Assisted Surgery, 2012; 8 (1): 1-6.

8. Edwards CA, Rusheen AE, Oh Y, Paek SB, Jacobs J, Lee KH, Dennis KD, Bennet KE, Kouzani AZ, Lee $\mathrm{KH}$, Goerss SJ. A novel re-attachable stereotactic frame for MRI-guided neuronavigation and its validation in a large animal and human cadaver model. Journal of Neural Engineering, 2018; 15 (6): 066003.

9. Songul Meltem CA, Turkmenoglu ON, Tanik C, Uysal E, Ozoner B, Kaldirimoglu SA, Musluman AM, Yilmaz A, Cavusoglu H, Bayindir C, Aydin Y. Computerized tomography-guided stereotactic biopsy of intracranial lesions: report of 500 consecutive cases. Turk Neurosurg. 2017; 27 (3): 395-400.

10. Alptekin O, Gubler FS, Ackermans L, Kubben PL, Kuijf ML, Kocabicak E, Temel Y. Stereotactic accuracy and frame mounting: A phantom study. Surgical Neurology International, 2019: 10.

11. Bernstein M, Parrent AG. Complications of CT-guided stereotactic biopsy of intra-axial brain lesions. Journal of Neurosurgery, 1994; 81 (2): 165-8.

12. Hall WA. The safety and efficacy of stereotactic biopsy for intracranial lesions. Cancer: Interdisciplinary International Journal of the American Cancer Society, 1998; 82 (9): 1749-55.

13. $\mathrm{Lu} \mathrm{CY}, \mathrm{Xu} \mathrm{ZS}, \mathrm{Ye} \mathrm{X}$. Evaluation of intraoperative MRI-assisted stereotactic brain tissue biopsy: a singlecenter experience in China. Chinese Neurosurgical Journal, 2019; 5 (1): 4.

14. Cheng G, Yu X, Zhao H, Cao W, Li H, Li Q, Li Z, Yin F, Liu R, Zhang J. Complications of stereotactic biopsy of lesions in the sellar region, pineal gland, and brainstem: A retrospective, single-center study. Medicine, 2020; 99 (8): e18572.

15. Hamisch CA, Minartz J, Blau T, Hafkemeyer V, Rueß D, Hellerbach A, Grau SJ, Ruge MI. Frame-based stereotactic biopsy of deep-seated and midline structures in 511 procedures: feasibility, risk profile, and diagnostic yield. Acta Neurochirurgica, 2019; 161 (10): 2065-71.

16. Sciortino T, Fernandes B, Nibali MC, Gay LG, Rossi M, Lopci E, Colombo AE, Elefante MG, Pessina F, Bello L, Riva M. Frameless stereotactic biopsy for precision neurosurgery: diagnostic value, safety, and accuracy. Acta Neurochirurgica, 2019; 161 (5): 967-74.

17. Smith JS, Quiñones-Hinojosa A, Barbaro NM, McDermott MW. Frame-based stereotactic biopsy remains an important diagnostic tool with distinct advantages over frameless stereotactic biopsy. Journal of Neuro-Oncology, 2005; 73 (2): 173-9.

18. Neumann JO, Campos B, Younes B, Jakobs M, Jungk C, Beynon C, von Deimling A, Unterberg A, Kiening K. Frame-based stereotactic biopsies using an intraoperative MR-scanner are as safe and effective as conventional stereotactic procedures. PloS one, 2018; $13(10)$.

19. Nishihara M, Sasayama T, Kudo H, Kohmura E. Morbidity of stereotactic biopsy for intracranial lesions. Kobe J Med Sci. 2011; 56 (4): E148-53.

\section{Additional Information}

Disclosures: Authors report no conflict of interest.

Ethical Review Board Approval: The study was conformed to the ethical review board requirements.

Human Subjects: Consent was obtained by all patients/participants in this study.

Conflicts of Interest:

In compliance with the ICMJE uniform disclosure form, all authors declare the following:

Financial Relationships: All authors have declared that they have no financial relationships at present or within the previous three years with any organizations that might have an interest in the submitted work.

Other Relationships: All authors have declared that there are no other relationships or activities that could appear to have influenced the submitted work. 
Address for Correspondence: Aurangzeb Kalhoro Jinnah Medical Dental College \& N.C.C.I., Karachi Email:draurangzebkalhoro@gmail.com

\section{AUTHORSHIP AND CONTRIBUTION DECLARATION}

\begin{tabular}{|l|l|l|}
\hline Sr.\# & Author's Full Name and Affiliation & Intellectual Contribution to Paper in Terms of: \\
\hline 1. & Aurangzeb Kalhoro & $\begin{array}{l}\text { Study design and methodology. } \\
\text { Paper writing, referencing, data calculations and Data collection and } \\
\text { calculations }\end{array}$ \\
\hline 2. & A. Sattar M. Hashim & $\begin{array}{l}\text { Analysis of data and interpretation of results etc. } \\
\text { Literature review and manuscript writing } \\
\text { Analysis of data and quality insurer }\end{array}$ \\
\hline
\end{tabular}

Date of Submission: 07-5-2020

Date of Revision: 31-05-2020

Date of Online Publishing: 30-06-2020

Date of Print: 30-07-2020 